\title{
Toxicity of newly isolated piperideine alkaloids from the red imported fire ant, Solenopsis invicta Buren, against the green peach aphid, Myzus persicae (Sulzer)
}

\author{
Tahir Rashid ${ }^{1}$, Jian Chen $^{2}$, Paul McLeod $^{3^{*}}$ \\ ${ }^{1}$ Extension/Research Demonstration Farm, Alcorn State University, Mound Bayou, USA \\ ${ }^{2}$ USDA-ARS, National Biological Control Laboratory, Stoneville, USA \\ ${ }^{3}$ Department of Entomology, University of Arkansas, Fayetteville, USA; \\ *Corresponding Author: pjmcleod@uark.edu
}

Received 10 June 2013; revised 24 July 2013; accepted 1 August 2013

Copyright (C 2013 Tahir Rashid et al. This is an open access article distributed under the Creative Commons Attribution License, which permits unrestricted use, distribution, and reproduction in any medium, provided the original work is properly cited.

\section{ABSTRACT}

The green peach aphid, Myzus persicae (Sulzer), is a major insect pest of many agronomic and horticultural crops and is distributed worldwide. Aphid management is often based on application of insecticides. However, the aphid is now resistant to many of these and much interest has recently developed in identification of novel alternative insecticides. Venom isolated from the red imported fire ant, Solenopsis invicta Buren, is composed of two groups of alkaloids, piperidines and piperideines, and has shown activity against many organisms including fungi, bacteria, mites and several insects. Prior to the study reported herein, no information on the venom's activity to Myzus persicae has been reported. Both of the alkaloids were active against $M$. persicae. The $24 \mathrm{~h} \mathrm{LC} \mathrm{L}_{50}$ values were116.6 and 91.5 ppm for the piperideine and piperidine extracts, respectively. Based on overlap of the $95 \%$ fiducial limits the LC $_{50}$ values for the two alkaloids did not significantly differ. At the high dosages, mortality occurred in as few as four hours and all treated aphids were dead by six hours. Little additional mortality was detected in the 48-h observation. Both piperideine and piperidine extracts isolated from red imported fire ant venom possess sufficient activity to cause death of green peach aphids and at high dosages, death occurs rapidly. In the search for new replacements to synthetic insecticides, these extracts may offer a novel but potentially successful alternative.
Keywords: Myzus persicae; Solenopsis invicta; Piperideine; Piperidine; Toxicity

\section{INTRODUCTION}

The green peach aphid, Myzus persicae (Sulzer), is a common pest of many agronomic and vegetable crops and has a worldwide distribution [1]. This highly polyphagous insect can cause direct injury to the plants by feeding on the leaves and extracting sap or indirectly injure plants by transmitting viruses [2,3]. It also secretes honeydew which attracts fungus causing the smutting of leaves and fruit [4]. The growth of sooty molds also hampers photosynthesis. M. persicae has a very high reproductive potential and can cause substantial injury to young plants thus causing eventual death [5]. The presence of aphids can cause contamination in processed vegetables and is subject to quarantine restrictions [6]. Systemic insecticides are frequently used to suppress $M$. persicae populations but are less effective in cooler temperatures [7]. Over time, M. persicae populations have developed resistance against synthetic insecticides [8,9]. Anstead et al. reported development of resistance in $M$. persicaeto more insecticides than any other insect [10].

Many biologically active compounds have been of great interest because of their activity against insect pests. Plant alkaloids, such as neem oil and nicotineare increasingly used as insecticides [11-13]. Certain mineral and essential oils are comparable to chemical insecticides in activity against $M$. persicae [14]. A number of ant species possess poison glands associated with the sting for defensive purposes [15]. Chemically this poison is proteinaceous or in the form of formic acid. But in some ant spe- 
cies, mostly the subfamily Myrmicinae, which includes the red imported fire ant, Solenopsis invicta Buren, the major component of the venom consists of alkaloids with only a fraction of protein [16]. The red imported fire ant produces venom that is not only active against humans but possesses a diversity of properties that are biologically active. The venom acts as a pheromone attractant [17], antimicrobial agent [18], and possesses insecticidal properties against numerous insects [19]. Alkaloid-based venom of $S$. invicta has been reported to possess antibacterial, antifungal and insecticidal activities [20]. The insecticidal and antibiotic properties of the raw venom were discovered in the late 1950's. The venom was highly active against the fruit fly, the housefly, a termite species, the boll weevil, rice weevil, and two species of mites. Using a paper-disc method, Blum et al. [19] demonstrated that a 1/50 dilution of the venom effectively inhibited the growth of Micrococcus pyogenes, Streptococcus pyogenes, Escherichia coli, Lactobacillus casei and a variety of molds.

The venom alkaloids extracted from the red imported fire ants have two groups of alkaloids, piperidines and piperideines. The activity of fire ant venom alkaloids may be the combinative effect of these two groups of alkaloids. It was found that Gram-positive bacteria were more sensitive to piperidine alkaloids than Gram-negative ones. Solenopsis invicta venom alkaloids also inhibited the germination and hyphal development of entomopathogenic fungi, Beauveria bassiana AF-4, B. bassiana 447, monosporal isolates of Metarhizium anisopliae, and Paecilomyces fumosoroseus. Anti-fungal activities of these new piperideine alkaloids against plant pathogenic fungus, such as P. ultimum has been investigated [21]. Chen et al. [16] found six new piperideine alkaloids in fire ants, including

2-methyl-6-tridecenyl-6-piperideine,

2-methyl-6-tridecyl-6-piperideine,

2-methyl-6-pentadecenyl-6-piperideine,

2-methyl-6-pentadecyl-6-piperideine,

2-methyl-6-heptadecenyl-6-piperideine,

and 2-methyl-6-heptadecyl-6-piperideine.This study was conducted to investigate biological activity of newly reportedpiperideine alkaloid component of $S$. invicta venom against M. persicae.

\section{MATERIALS AND METHODS}

\subsection{Plant and Aphid Source}

Pepper cv "Jalapeno" plants were produced in 9-cm plastic pots containing potting soil (Scott's Moisture Advantage, Scott's Company, Marysville, $\mathrm{OH}$ 43041) from seed obtained from the Neseed Company, Hartford, CT 06120. Plants were produced from Sept 2009 until Mar 2010 in a greenhouse located at the University of Ar- kansas Main Experimental Station, Fayetteville, Arkansas. Temperature was maintained between $25^{\circ} \mathrm{C}$ and $29^{\circ} \mathrm{C}$ with natural light. After about six weeks plants that had eight to ten true leaves were moved to the laboratory and infested with green peach aphids from a laboratory culture maintained on pepper. Infested leaves were cut from the culture plants and placed on each test plant. Aphids were allowed to move to the test leaves. After a one-week establishment period plants were searched for aphids. Those containing leaves with at least 20 adult apterous aphids were selected for testing. Immediately prior to testing, individual leaves were removed from the plant with a razorblade. Immature aphids were removed with a camel hair brush.

\subsection{Extraction and Purification of Piperidine and Piperideine Alkaloids}

The method described by Li et al. [21] was used to extract and purify fire ant venom alkaloids. Briefly, $2.5 \mathrm{~g}$ workers of the imported fire ant were extracted in $15 \mathrm{ml}$ hexane three times and the pooled extract was concentrated to about $0.5 \mathrm{ml}$ under air flow. A flash chromatography system (Isolera Four, Biotage, LLC, Charlotte, North Carolina, USA) with a SNAP silica gel cartridge (10 g) was used to isolate and purify the piperidine and piperideine alkaloids. The cartridge was first equilibrated with $45 \mathrm{ml}$ hexane before the sample was loaded. A gradient of hexane and acetone was used as a mobile phase at a flow rate of $12 \mathrm{ml} / \mathrm{min}$. Components and purity of purified alkaloids were checked using gas chromatography-mass spectrometry. The purity was $99.8 \%$ for piperidine alkaloids and $87.8 \%$ for piperideine alkaloids.

\subsection{Bioassay}

Each of the two extracts, i.e., piperideines (18.233 mg) and piperidines (20.613 mg), was dissolved in $0.5 \mathrm{ml}$ acetone to produce the initial concentrations of 46,008 and 52,014 ppm extract:acetone, respectively. Subsequent serial dilutions were made with acetone and ranged from 4600 to $23 \mathrm{ppm}$ for the piperideines and 2600 to $5 \mathrm{ppm}$ for the piperidines. Each concentration was applied with an ISCO Model $\mathrm{M}$ microapplicator, ISCO Company, Lincoln, NE 68507, fitted with a glass B-D syringe and 27 gauge needle, Becton, Dickinson and Company, Rutherford, NJ 07070. The volume of the application was 0.337 ul. Applications were made with the aid of a desk magnifying light. Although the application was applied directly to the dorsal surface of each aphid, some of the mixture spread from the aphid to the leaf surface due to the small aphid size. After treatment, leaves were placed in 28-ml plastic cups, Comet Products, Inc., Chelmsford, MA 01824, with a 2.5-cm diameter disk of moist blotter paper. Cups were capped and held in an environmental 
chamber set at $26^{\circ} \mathrm{C}$ and $12: 12$ h photo phase. Mortality was assessed at 24 and 48 h by prodding each aphid with a camel hair brush. Lack of movement was used as the criterion for judging death. Additional observations were made at hourly intervals to establish the time of death. Data were analyzed with Proc Probit (SAS 9.1, SAS Institute, Cary, NC).

\section{RESULTS AND DISCUSSION}

Both of the tested extracts, i.e., piperideines and piperidines, were active against the green peach aphid (Table 1). Chi Square values were significant for both extracts at one and two days after treatment (DAT) indicating that increasing dosage caused an increase in mortality. Aphid death occurred rapidly. In as few as four hours, approximately 50\% mortality was observed with aphids treated with the high dosages of piperideines (4600 ppm) and piperidines (2600 ppm). At six hours post treatment $100 \%$ of the aphids receiving the high dosages were dead. Counts taken 1 DAT produced LC $_{50}$ values of 116.6 and $91.5 \mathrm{ppm}$ for the piperideine and piperidine extracts, respectively. These values did not statistically differ based on overlap of the 95\% fiducial limits. The 1 DAT LC 95 values were 2480 and $824.8 \mathrm{ppm}$ for the piperideine and piperidine extracts, respectively. Although the $\mathrm{LC}_{95}$ value for the piperideine extract was approximately three times higher than that for the piperidine extract, the fiducial limits overlapped indicating no significant difference. Activity was not greatly increased in the 2 DAT observation. The $\mathrm{LC}_{50}$ values were 89.3 and 48.5 ppm for thepiperideine and piperidine extracts, respectively (Table 1). Again, based on fiducial limit overlap, the two $\mathrm{LC}_{50}$ values did not statistically differ. The $\mathrm{LC}_{95}$ value for the piperidine extract was $396.8 \mathrm{ppm}$ and this was statistically lower or more active against the green peach aphid than the piperideine extract.

Table 1. Dosage response of green peach aphid to piperideine and piperidine extracts.

\begin{tabular}{|c|c|c|c|c|c|}
\hline \multicolumn{6}{|c|}{1 DAT } \\
\hline Extract & $n$ & slope $( \pm S E)$ & $\begin{array}{c}\mathrm{LC}_{50} \\
(95 \% \mathrm{FL})\end{array}$ & $\begin{array}{c}\mathrm{LC}_{95} \\
(95 \% \mathrm{FL})\end{array}$ & $\chi^{2}$ \\
\hline piperideines & 877 & $1.24(0.08)$ & $\begin{array}{c}116.3 \\
(92.3-143.1)\end{array}$ & $\begin{array}{c}2480 \\
(1792-3713)\end{array}$ & 233.08 \\
\hline piperidines & 933 & $1.72(0.22)$ & $\begin{array}{c}91.5 \\
(54.5-146.3)\end{array}$ & $\begin{array}{c}824.8 \\
(425.9-2803)\end{array}$ & 63.28 \\
\hline \multicolumn{6}{|c|}{2 DAT } \\
\hline Extract & $n$ & slope $( \pm S E)$ & $\begin{array}{c}\mathrm{LC}_{50} \\
(95 \% \mathrm{FL})\end{array}$ & $\begin{array}{c}\mathrm{LC}_{95} \\
(95 \% \mathrm{FL})\end{array}$ & $\chi^{2}$ \\
\hline piperideines & 877 & $1.37(0.16)$ & $\begin{array}{c}89.3 \\
(49.0-139.5)\end{array}$ & $\begin{array}{c}1404 \\
(749.9-4118)\end{array}$ & 78.23 \\
\hline piperidines & 933 & $1.80(0.12)$ & $\begin{array}{c}48.5 \\
(41.1-56.8)\end{array}$ & $\begin{array}{c}396.8 \\
(308.4-542.8)\end{array}$ & 229.48 \\
\hline
\end{tabular}

The green peach aphid poses a serious threat to many agronomic and horticultural crops and due to the insect's ability to rapidly develop resistance to different groups of insecticides, efforts to screen new groups of insecticides for green peach aphid toxicity will continue. Results reported herein indicate that the venom alkaloid extracts from the red imported fire ant are toxic to the aphid. Further, the alkaloids are rapid acting and can produce death in as few as four hours. This rapid activity is comparable to currently registered synthetic insecticides. The data reported herein indicate that both tested extracts offer potential for development as new insecticides directed at the green peach aphid. Although, many questions such as harmful effects on non-target species and the environment must be addressed, the initial toxicity testing has identified the red imported fire ant alkaloids as a potential new insecticide group.

\section{CONCLUSION}

In conclusion, both piperideine and piperidine extracts isolated from red imported fire ant possess sufficient activity to cause death of green peach aphids. Death occurs rapidly in as little as four hours. In the search for new replacements to synthetic insecticides, these extracts may offer a novel but potentially successful alternative.

\section{REFERENCES}

[1] Ramsey, J., Wilson, A.C., De Vos, M., Sun, Q., Tamborindeguy, C., Winfield, A., Malloch, G., Smith, D.M., Fenton,B., Gray, S.M. and Jander, G. (2007) Genomic resources for Myzus persicae: EST sequencing, SNPidentification, and microarray design. BMC Genomics, 8, 423. http://dx.doi.org/10.1186/1471-2164-8-423

[2] Flanders, K., Radcliffe, E. and Ragsdale, D. (1991) Potato leafroll virus spread in relation to densities of green peach aphid (Homoptera: Aphididae): Implications for management thresholds for Minnesota seed potatoes. Journal of Economic Entomology, 84, 1028-1036.

[3] Tagu, D., Klingler, J.P., Moya, A. and Simon, J. (2008) Early progress in aphid genomics and consequences for plant-aphid interactions studies. Molecular Plant-Microbe Interactions, 21, 701-708. http://dx.doi.org/10.1094/MPMI-21-6-0701

[4] Gray, S.M. and Gildow, F. (2003) Luteovirus-aphid interactions. Annual Reviews Phytopathology, 41, 539-566. http://dx.doi.org/10.1146/annurev.phyto.41.012203.10581 $\underline{5}$

[5] Petitt, F. and Smilowitz, Z. (1982) Green peach aphid feeding damage to potato in various plantgrowth stages. Journal of Economic Entomology, 75, 431-435.

[6] Stewart, J., Aharoni,Y., Hartsell, P. and Young, D. (1980) Acetaldehyde fumigation at reducedpressures to control the green peach aphid on wrapped and packed head lettuce. Journal of Economic Entomology, 73, 149-152.

[7] McLeod, P. (1991) Influence of temperature on trans- 
laminar and systemic toxicities of aphicidesfor green peach aphid (Homoptera: Aphididae) suppression on spinach. Journal of Economic Entomology, 84, 15581561.

[8] Blackman, R. and Devonshire, A. (1978) Further studies of the genetics of thecarboxylesteraseregulatory system involved in resistance to organophosphorous insecticides in Myzus persicae (Sulzer). Pesticide Science, 9, 517-521. http://dx.doi.org/10.1002/ps.2780090605

[9] Bauernfeind, R. and Chapman, R. (1985) Nonstable parathion and endosulfan resistance in green peach aphids (Homoptera: Aphididae). Journal of Economic Entomology, 78, 516-522.

[10] Anstead, J.A., Williamson, M.S. and Denholm, I. (2005) Evidence formultiple origins of identical insecticide resistance mutations in theaphid Myzus persicae. Insect Biochemistry and Molecular Biology, 35, 249-256. http://dx.doi.org/10.1016/j.ibmb.2004.12.004

[11] Ahmad, M., Oßiewatsch, H.R. and Basedow, T. (2003) Effects of neem-treated aphids as food/hosts on their predators and parasitoids. Journal of Applied Entomology, 127, 458-464. http://dx.doi.org/10.1046/j.0931-2048.2003.00779.x

[12] Yasinok, A.E., Sahin, F.I., Eyidogan, F., Kuru, M. and Haberal, M. (2009) Grafting tomato planton tobacco plant and its effect on tomato plant yield and nicotine content. Journal of the Science of Food and Agriculture, 89, 1122-1128. http://dx.doi.org/10.1002/jsfa.3555

[13] Sharp, D.N., Lentz-Ronning,A.J., Barron, J. and Adler, L.S. (2009) The Effect of larval diet and sex on nectar nicotine feeding preferences in Manduca sexta (Lepidoptera: Sphingidae). The Florida Entomologist, 92, 374-376. http://dx.doi.org/10.1653/024.092.0225

[14] Yankova, V., Markova, D. and Todorova, V. (2009) Biological activity of certain oils in control of green peach
aphid(Myzus persicae Sulz.) on pepper. Acta Horticulturae, 830, 619-625.

[15] Blum, M.S. (1987) Biosynthesis of arthropod exocrine compounds. Annual Reviews Phytopathology, 32, 381-413. http://dx.doi.org/10.1146/annurev.en.32.010187.002121

[16] Chen, J., Cantrell, C.L., Shang, H. and Rojas, M.G. (2009) Piperideine alkaloids from the poison gland of the red imported fire ant (Hymenoptera: Formicidae). Journal of Agricultural and Food Chemistry, 57, 3128-3133. http://dx.doi.org/10.1021/jf803561y

[17] Vander Meer, R.K., Glancey, B.M., Lofgren, C.S., Glover, A., Tumlinson, J.H. and Rocca, J. (1980) The poison sac of red imported fire ant queens: Source of a pheromone attractant. Annals of the Entomological Society of America, 73, 609-612.

[18] Jouvenaz, D.P., Blum, M.S. and MacConnell, J.G. (1972) Antibacterialactivity of venom alkaloids from the imported fire ant Solenopsis invicta Buren. Antimicrobial Agents and Chemotherapy, 2, 291-293. http://dx.doi.org/10.1128/AAC.2.4.291

[19] Blum, M.S., Walker, J.R., Callahan, P.S. and Novak, A.F. (1958) Chemical, insecticidal and antibiotic properties of fire ant venom. Science, 128, 306-307. http://dx.doi.org/10.1126/science.128.3319.306-a

[20] Jones, T.H., Blum, M.S. and Fales, H.M. (1982) Ant venom alkaloids from Solenopsis and Monomorium species. Recent developments. Tetrahedron, 38, 1949-1958. http://dx.doi.org/10.1016/0040-4020(82)80044-6

[21] Li, S., Jin, X. and Chen, J. (2012) Effects of piperidine and piperideine alkaloids from the venom of red imported fire ants, Solenopsis invicta Buren, on Pythium ultimum Trow growth in vitro and the application of piperideine alkaloids to control cucumber damping-off in the greenhouse. Pest Management Science, 68, 1546-1552. http://dx.doi.org/10.1002/ps.3337 